

\title{
IDENTIFICATION OF DISRUPTIVE EXPONENTIAL TECHNOLOGIES OF INDUSTRY 4.0
}

\author{
Dominika Koncová ${ }^{1}$, Iveta Kremeňová ${ }^{2}$
}

\begin{abstract}
As the present is connected to the development and implementation of technologies that fall under Industry 4.0, it is necessary to get acquainted with the main areas of interest. The paper identifies individual disruptive exponential technologies with their examples of use in specific areas and the issue of inconsistency in definition of artificial intelligence (AI) is discussed in more detail. In conclusion, there is definition of AI created by authors.
\end{abstract}

Keywords: Industry 4.0, technologies of Industry 4.0, Artificial Intelligence.

\section{Introduction}

The present is associated with the implementation of new technologies, for example the implementation of new production procedures and processes in companies and the effort to reduce environmental, economic, technological and personnel burden. It is much easier for individual companies to implement automation of individual processes and transfer individual documents to digital form, which will significantly reduce the demand for employees for traditional jobs, but there is an increase in the demand for technological equipment of the company. Industry 4.0 is often associated with process automation, the introduction of innovations and the transition from paper to digital form of documents, whether in the field of accounting, project solutions, correspondence, etc. Many people, either scientists or general population, call automation and digitization a relatively new concept of artificial intelligence (AI), but as time goes on and new facts emerge, the link between automation and digitization is no longer sufficient to explain an AI.

This paper is devoted to the issue of identifying and specifying concepts such as Industry 4.0, the technologies of this industrial revolution, artificial intelligence and its more precise definition. Subsequently, the paper also clarifies the issue of some technologies that can be used by individual companies on their websites, especially if as the subjects of interest, pose companies providing services, in connection with AI. In conclusion of this paper, there is by authors created definition of artificial intelligence based on the definitions discussed in the paper.

\section{Purpose and methodology}

To identify the technologies used in Industry 4.0 as well as to find out more information about artificial intelligence, for which it is necessary to find a suitable definition for the present times, are the main goals of this paper. The paper uses excerpting from

\footnotetext{
${ }^{1}$ Ing. Dominika Koncová, University of Zilina, Faculty of Operation and Economics of Transport and Communications, Department of Communications, Univerzitna 8215/1, 01026 Zilina, Slovakia, e-mail: dominika.koncova@stud.uniza.sk

2 doc. Ing. Iveta Kremeňová, PhD., University of Zilina, Faculty of Operation and Economics of Transport and Communications, Department of Communications, Univerzitna 8215/1, 01026 Zilina, Slovakia,

e-mail: iveta.kremenova@fpedas.uniza.sk
} 
secondary sources of literature to gain theoretical knowledge base of the issue of artificial intelligence in relation to Industry 4.0. Furthermore, the synthesis of the acquired knowledge is used in the paper and on the basis of induction and deduction the areas of suitable use of AI are evaluated.

\section{Industry 4.0 and its technologies}

Industry 4.0 can be defined as a new level of organization and control within the entire value chain of products and their life cycle. This value chain is aimed at increasing individualized customer requirements. [1] [2] Like other sectors of the economy, industry has gone through several stages of development and has implemented many innovations in order to streamline processes and reduce errors by optimizing these processes.

Many consider Industry 4.0 only as an extension of Industry 3.0. However, there are reasons why today's transformation in industry is considered as the arrival of Industry 4.0 [3]: character;

- the speed - the development of Industry 4.0 has a predominantly exponential

- the range - its extensive intervention is in almost all types of economy, and the breadth and depth of such changes include the transformation of entire systems (from production to management) with intervention in countries all around the world;

- the impact of systems - systems are braced by technical discoveries in areas such as: materials science, biotechnology and nanotechnology, robotics, artificial intelligence (AI) and innovations in the field of quantum computing. [3]

\subsection{Technologies of Industry 4.0}

The technologies used in Industry 4.0 are diverse in nature. But the use in computing technology, during conducting operations, and their connection to other devices they have in common. These technologies can be included in the categories listed in Table 1 also with their examples of use, resp. further use.

Table 1 Technologies used in Industry 4.0 and examples of its use.

\section{Technologies}

\begin{tabular}{|c|c|}
\hline Technologies & Examples of use \\
\hline $\begin{array}{l}\text { Cyber } \\
\text { systems }\end{array}$ & $\begin{array}{l}\text { - } \text { - healthcare and biomedical systems - medical monitoring [5], [7] } \\
\text { - } \text { smart power grid } \\
\text { - } \quad \text { industrial control systems } \\
\text { - in avionics - automatic pilot } \\
\text { - } \quad \text { applications for tracking and further analysing emissions of } \mathrm{CO}_{2} \text { [8] } \\
\text { - } \quad \text { smartphones }\end{array}$ \\
\hline Internet of Things & $\begin{array}{l}\text { - consumer applications of IoT in: smart home, elder care [9] } \\
\text { - organisational applications of IoT in: Internet of Medical Things (IoMT), } \\
\text { transportation, vehicular communication systems (V2X) [10], building and } \\
\text { home automation, Industrial internet of things, agriculture and } \\
\text { manufacturing, maritime IoT } \\
\text { - industrial applications of IoT in: deployments in metropolises, energy } \\
\text { management and environmental monitoring, etc. } \\
\text { - military applications of IoT in: Internet of Military Things (MIOT) [11], } \\
\text { Internet of Battlefield Things (IoBT), Ocean of Things [12] } \\
\text { digitisation of products }\end{array}$ \\
\hline Internet of Services & $\begin{array}{ll}\text { - } & \text { cloud computing [4] } \\
\text { - } & \text { data science [13] } \\
\text { - } & \text { service oriented web [13] }\end{array}$ \\
\hline
\end{tabular}




\begin{tabular}{|c|c|}
\hline Big Data & $\begin{array}{l}\text { - } \text { computer-aided diagnosis in healthcare } \\
\text { - } \text { IT operations analytics (ITOA) } \\
\text { - } \text { data analysis } \\
\text { - } \\
\text { - } \\
\text { - } \text { data mining [14] } \\
\text { - } \text { distributed databases } \\
\text { - } \\
\text { advanced algorithms }\end{array}$ \\
\hline Cloud Computing & $\begin{array}{ll}\text { - } & \text { Infrastructure as a service (IaaS) } \\
\text { - } & \text { Platform as a service (PaaS) } \\
\text { - } & \text { Software as a service (SaaS) [4] } \\
\text { - } & \text { Mobile "backend" as a service (MBaaS) [15] } \\
\text { - } & \text { Function as a service (FaaS) as a part of serverless architectures [16] }\end{array}$ \\
\hline $\begin{array}{l}\text { Product Life Cycle } \\
\text { Management systems }\end{array}$ & $\begin{array}{l}\text { - In organisations for: utility distribution networks, civil engineering projects } \\
\text { [17], product life-cycle management - marketing (PLCM), CRM-customer } \\
\text { relationship management), supply chain management (SCM), enterprise } \\
\text { resource planning (ERP) product planning and development (PLM) [18] }\end{array}$ \\
\hline Digital manufacturing & $\begin{array}{ll}\text { - } & \text { 3D printing } \\
\text { - } & \text { Additive manufacturing [19] }\end{array}$ \\
\hline Digital twin & $\begin{array}{l}\text { building information - modelling processes (creating digital twins to real } \\
\text { buildings) } \\
\text { - virtual patient [20] }\end{array}$ \\
\hline
\end{tabular}

Cyber-physical systems (CPS) - were designed for the collection, subsequent processing and distribution of digital data, using built-in tools. They form the basis for the Internet of Things (IoT) and, when combined with the Internet of Services (IoS), form the platform of basis for Industry 4.0. [4] [5] Internet of Things (IoT) - so called "things" in the field of IoT can be understood as connections between hardware and software with acquired data and provided services. Control, of those things, is possible thanks to the built-in module providing WIFI connection in such devices. [4] [9] [10] Internet of Services (IoS) - provides an infrastructure that uses the Internet as an intermediary medium, through which it offers, sells and in some cases even implements services. [4] [13]

Big Data - this technology is used to achieve predictive production to reduce downtime between production and sales to a minimum, which requires profit, processing, analysis and evaluation of huge amounts of data. [4] [14] Cloud Computing - technology is based on the provision of services or programs, which are provided via the Internet and stored on servers. Users are able to access them through a web browser or the client of a specific application. [4] [15] [16] While the cloud can be understood as a service with unlimited availability via the Internet, cloud computing can already be understood as a specialized service provided via the Internet, in which the service provider provides users with sharing and program use, or applications that may be of a different nature. [6]

Product Lifecycle Management (PLM) systems - obtain and integrate information from both the vertical and horizontal structure of the company. These systems are designed to effectively manage the information collected through PLM software. [4] [17] [18] Digital manufacturing - in its complex form, is mainly used to achieve the long-term benefits of PLM. Technologists are able to virtually create, through digital production systems, a comprehensive scheme of the production process, from the used tools and gears, production lines, logistics and specific workplaces providing production to the ergonomic solutions themselves. [4] [19] Digital twin - represents the transfer of a real physical object, e.g. product, in digital form. It works on the basis of processing data obtained from sensor devices that have been installed on or in physical objects in order to optimize them. The very concept 
of the digital twin works on 3 basic pillars: physical products in real reality, their virtual copies in virtual reality and the connection of acquired data and information to connect both types of products - physical with virtual. [4] [20]

Exponential technologies - bring along rapid growth in productivity and efficiency. They are used mainly in production-related areas where there is a high degree of repeatability. [4] Examples of such technologies are:

- biotechnology and neurotechnology, nanotechnology;

- $\mathrm{AI}$ and advanced robotics;

- drones and 3D printing, which can be used e.g. in logistics together with sensoring;

- new ICT (information and communication technologies), mobile technologies and others. [4] [21]

In essence, these are the technologies listed in Table 1. Such technologies shall be considered disruptive to all industrial sectors in terms of demand for occupations and skills. [21]

\subsection{Artificial intelligence}

Artificial intelligence is a term that has been present in both scientific and ordinary communication for several decades. It is a technology that simulates human intelligence in programmed machines to mimic either their behavior or their activities. [22] Many authors of AI explain artificial intelligence differently. It depends mainly on the fact that its understanding and scope have changed over time.

Initially, AI was considered a technology that linked automation and digitization. However, it depends on the level of digitization and a suitably designed algorithm, whether it is AI or just a sufficiently and correctly written program that the specific device executes. Wei [23] e.g. states that artificial intelligence is only a small part of digitization, while Balakarthiga [24] sees AI as just another disruptive Industry 4.0 technology that has a huge impact on the future of digital company transformation. The Oxford English Dictionary [25] understands $\mathrm{AI}$ in terms of production as "the theory and development of computer systems able to perform tasks normally requiring human intelligence". The European Parliament defines AI as: "the ability of a device to display human-like abilities such as thinking, learning, planning and creativity. Thanks to artificial intelligence, technical systems are able to distinguish the environment in which they find themselves and solve what they recognize as a problem, while acting in order to achieve a specific goal. The computer receives data prepared or collected through its sensors (eg cameras), processes it and responds. Artificial intelligence systems are able to work autonomously and adapt their behavior to some extent on the basis of an analysis of previous steps."[27]

Therefore, it can be argued that AI is no longer just a simple automation associated with digitization, but has relatively high demands on the use of appropriate algorithms that provide some form of self-learning, self-healing, etc., while also being implemented in robotics, in automated guided vehicles (AGV) and many others.

AI can be divided from several points of view, for example into strong AI and weak AI, respectively to the narrow AI, the general AI (AGI) and superintelligence. [26] Each of these types of AI has its specifics, potential, but also poses threats. Furthermore, AI is divided into 2 types: software AI (search engines, virtual assistants) and built-in devices AI (robots, drones, AGV and others). And there could be further dividing, but those are not the subject of interest for this paper.

Artificial intelligence can be used in several fields of interest, such as healthcare, agriculture and food production, transport (air transport, rail transport), but also in areas such as services, public administration or manufacturing. [27] Within the services, the possibility of using AI is also possible in the postal sector, where it can be used, among other things, for 
sorting shipments using DeepParse. However, its use is still only in the initial stages in postal companies. [28]

\section{Conclusion}

The technologies that are used and further developed in Industry 4.0 are disproportionately diverse and significantly progressive in relation to previous industrial revolutions. Industry 4.0 has brought with it countless innovations, not only in areas such as healthcare, industry, military, informatics and cybernetics, but also in the services and production processes of individual products. Despite the relatively long existence of artificial intelligence term in its initial stages, since 1956, its real use in real life and in production processes is very limited and relatively slowly comes to the fore.

Surprisingly, despite the existence of the term of AI for more than 60 years, there is still no specific definition that captures AI. Therefore, by combining these aforementioned secondary sources of information, it can be argued that "artificial intelligence is the ability of a device (e.g. a machine) to have intellect and capabilities at the level of the human brain as well as the ability to analyze, evaluate and provide solutions, depending on the level of used $A I$ '. Further examination is, however, needed to bring this concept closer to its true form.

\section{References}

[1] Rüßmann, M., Lorenz, M., Gerbert, P., Waldner, M.: Industry 4.0: The Future of Productivity and Growth in Manufacturing Industries, (April 09, 2015) pp. 1-14.

[2] Vaidya, S., Ambad, P., Bhosle, S. (2018). Industry 4.0-a glimpse. In: Procedia Manufacturing, 20, pp. 233-238.

[3] Prečo Industry 4.0. Accessed online from: <http://industry4.sk/o-industry-4-0/co-jeindustry-4-0/>.

[4] Technológie. Accessed online from: <http://industry4.sk/o-industry-4-0/technologie/>.

[5] Baheti, R., Gill, H. 2011. Cyber-physical systems. The impact of control technology, 12(1), 161-166.

[6] Cloud. 2020. It-Slovnik.cz. Accessed online from: <https://it-slovnik.cz/pojem/cloud $>$.

[7] Khaitan, S. K., McCalley, J. D. 2014. Design techniques and applications of cyberphysical systems: A survey. IEEE Systems Journal, 9(2), 350-365.

[8] Froehlich, J., Dillahunt, T., Klasnja, P., Mankoff, J., Consolvo, S., Harrison, B., Landay, J. A. April, 2009. UbiGreen: investigating a mobile tool for tracking and supporting green transportation habits. In Proceedings of the sigchi conference on human factors in computing systems (pp. 1043-1052).

[9] Guhathakurta, R. (2016). How IoT's Are Changing the Fundamentals of'Retailing'. Trak. in-Business of Tech, Mobile \& Startups in India.

[10]Han, S., He, Y., Ding, Y. (2020, December). Enable an Open Software Defined Mobility Ecosystem through VEC-OF. In 2020 IEEE 20th International Conference on Software Quality, Reliability and Security Companion (QRS-C) (pp. 229-236). IEEE.

[11]Yushi, L., Fei, J., Hui, Y. (2012, May). Study on application modes of military Internet of Things (MIOT). In 2012 IEEE international conference on computer science and automation engineering (CSAE) (Vol. 3, pp. 630-634). IEEE.

[12]Oussama, M. H. Internet of Things (IoT) Automatic Weather Station. Master thesis. 2020. $94 \mathrm{p}$.

[13]K Saini, N., Internet of Services: the ultimate goal of Internet of Things. 2015. Online, 2020. Linkedin. 
[14]Pllana, S., Janciak, I., Brezany, P., Wohrer, A. September, 2011. A survey of the state of the art in data mining and integration query languages. In 2011 14th International Conference on Network-Based Information Systems (pp. 341-348). IEEE.

[15]Tan, A. 2012. FatFractal ups the ante in backend-as-a-service market. Techgoondu. com. Retrieved 8.4.2021.

[16]Roberts, M. 2018. Serverless Architectures. martinFowler.com. Retrieved 8.4.2021.

[17]All About PLM. 2021. CIMdata.com. Retrieved 8.4.2021 from: $<$ https://www.cimdata.com/en/resources/about-plm $>$.

[18]Merticaru jr, V., Musca, G., Axinte, E. (2008). PLM in Relation to SCM and CRM, for Integrating Manufacturing with Sustainable Industrial Design. Proceedings of ICOVACS 2008, 109-118. From the original: Evans, M. 2004. In 2004, will PLM and SCM still be recognisable TLAs?

[19]Industry 4.0: 7 Real-World Examples of Digital Manufacturing in Action. 2019. AMFG.ai. 2020. Retrieved 8.4.2021 from <https://amfg.ai/2019/03/28/industry-4-0-7real-world-examples-of-digital-manufacturing-in-action/>.

[20]Bruynseels, K., Santoni de Sio, F., \& van den Hoven, J. 2018. Digital twins in health care: ethical implications of an emerging engineering paradigm. Frontiers in genetics, 9, 31.

[21]Bongomin, O., Gilibrays Ocen, G., Oyondi Nganyi, E., Musinguzi, A., Omara, T. 2020. Exponential disruptive technologies and the required skills of industry 4.0. Journal of Engineering, 2020.

[22]Frankenfield, J. 2021. Artificial Intelligence (AI). Investopedia.com. Retrieved 7.4.2021 from: $<$ https://www.investopedia.com/terms/a/artificial-intelligence-ai.asp $>$.

[23]Interview: Kaiser, M. and Wei, M. 2016. Artificial Intelligence is an important Component of Digital Transformation. InnovationManagement.se. 2021. Retrieved 7.4.2021 from: < https://innovationmanagement.se/2016/11/02/artificial-intelligencedigital-transformation/>.

[24] Balakarthiga, M. AI in Digitization. blog.MobiusServices.com. 2020. Retrieved 7.4.2021 from: <https://blog.mobiusservices.com/ai-in-digitization/>.

[25]AI in production. OECD (2018), OECD Science, Technology and Inovation Outlook 2018: Adapting to Technological and Societal Disruption, OECD Publishing, Paris. From the original: Oxford English Dictionary.

[26]Umelá inteligencia - svet $v$ ohrození? 2020. Robopol.sk. Retrieved 8.4.2021 from: $<$ https://robopol.sk/blog/umel\%C3\%A1-inteligencia-svet-v-ohrozen\%C3\%AD>.

[27]Umelá inteligencia: definícia a využitie. Európsky parlament. 2021. Retrieved 8.4.2021 from: $<$ https://www.europarl.europa.eu/pdfs/news/expert/2020/9/story/20200827STO858 04/20200827STO85804_sk.pdf>.

[28]Abid, N., ul Hasan, A., \& Shafait, F. (2018, December). DeepParse: A Trainable Postal Address Parser. In 2018 Digital Image Computing: Techniques and Applications (DICTA) (pp. 1-8). IEEE.

\section{Grant support}

The Paper is published with the support of project 1/0518/19. This research has been further supported by the University of Zilina in the scope of Institutional research1/KS/2020 and Project CIS by Ministry of Educations SR. 